\title{
An estimation of the prevalence of intellectual disabilities and its association with age in rural and urban populations in India
}

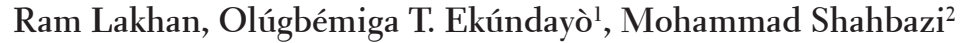 \\ Department of Epidemiology, ${ }^{2}$ Department of Behavioral Health and Education, School of Health Sciences, College of Public Service, \\ Jackson State University, Jackson, Mississippi, ${ }^{1}$ Department of Public Health, Eastern Washington University, Cheney, Washington, USA
}

\section{ABSTRACT}

Background: Intellectual disability (ID) is a global public health concern. Prevalence of ID and its association with age and other demographic factors is required for planning purposes in India. Objective: This study analyzed the age-adjusted prevalence of ID in rural and urban populations and its correlation with age in children and adults. Materials and Methods: Disability data published in the report (2002) of National Sample Survey Organization were analyzed, using $Z$-test to measure differences in age-adjusted prevalence. Spearman rho was calculated to determine strength and direction of the association, and regression analysis was used to predict prevalence rate, based on age in rural and urban population settings. Results: Overall, India has a prevalence of 10.5/100o in ID. Urban population has slightly higher rate $(11 / 1000)$ than rural $(10.08 / 1000 ; P=0.044)$. Age was found to be highly correlated with prevalence of ID in rural children $(\varrho=0.981, P=0.019)$ as well as in children $(\varrho=-0.954, P=0.000)$ and adults $(\varrho=-0.957$, $P=0.000$ ) in urban population. The possibility of confounding or the existence of covariates for children in urban settings was noted. Conclusion: Results of this study match findings in other epidemiological studies. However, multistage, large-scale studies are recommended for investigating prevalence rates with different severity levels of ID.

Key words: Age, confounding, covariates, India, intellectual disability, National Sample Survey Organization report, population studies, prevalence, rural, urban

\section{Introduction}

The Prevalence of intellectual disabilities (ID) in India is not well known. India has the world's largest children population who are at higher risk of developmental disabilities. ${ }^{[1-3]}$

The prevalence of ID in India varies by age, gender, population-type, and place of residence. ${ }^{[4-12]}$ These demographic and geographic factors influence awareness of ID, its prevention, health care, and rehabilitation services, which further impact its incidence and

\begin{tabular}{|l|l|}
\hline \multicolumn{2}{|c|}{ Access this article online } \\
\hline Quick Response Code: & Website: \\
\hline & www.ruralneuropractice.com \\
\cline { 2 - 3 } & \\
\hline
\end{tabular}

prevalence. ${ }^{[1,2,11,13-16]}$ The burden of chronic and infectious diseases, poverty, poor sanitation, poor access to health care, rapidly growing population, pollution, and exposure to harmful chemicals increase the risk of ID in the nation. ${ }^{[11,12,17-20]}$

Previous studies have documented varied prevalence rates for ID in India, ranging between 1.7 cases/1000 and 32 cases/1000. ${ }^{[4-10]}$ This variation may have occurred due to differences in diagnostic criteria, case definition, sample size, and survey methods applied in the studies. ${ }^{[4,5,10-12,16]}$

The population of India is very large, thus very small difference in prevalence rate can make a huge difference in the total number of people with ID, further impacting state and national level polices and budget allocation to the disability sector.

The issue of prevalence is very important for several reasons, including population prevention intervention

Address for correspondence:

Mr. Ram Lakhan, Doctoral Candidate in Public Health (Epidemiology). Department of Epidemiology and Biostatistics, School of Health Sciences, College of Public Service, Jackson State University, 350, West Woodrow Wilson Drive, Jackson, MS 39213, USA. E-mail: ramlakhan15@gmail.com 
planning and education, rehabilitation planning, and health care services. ${ }^{[11,12]}$ Accurate estimation of ID prevalence can help policy makers formulate appropriate welfare policies and allocate budget accordingly. Healthcare, rehabilitation, educational, vocational and social needs of ID population vary with their age. The larger population live in rural settings in India with significantly higher rates of poverty, inaccessibility of health care and rehabilitation services compared to urban settings. The difference in prevalence between urban and rural settings with regard to age is needed for planning and development of services. Understanding of prevalence in rural and urban population can also help public health officials to develop appropriate preventive programs.

\section{Objective}

This study examines the correlation between age and prevalence of ID in children and adults and compares between rural and urban populations in India.

\section{Materials and Methods}

Prevalence data from the National Sample Survey Organization (NSSO) 2002 were used for this study. ${ }^{[12]}$ The survey was conducted by the Indian Ministry of Social Justice and Empowerment. Known as NSS $58^{\text {th }}$ round, report number 485 (58/26/1) Disabled Person in India. ${ }^{[21]}$ The report is freely available in the public domain and is the NSSO's latest survey report available on the prevalence of ID in India. Referred to as mental disability in the report, it was the $1^{\text {st }}$ time the Indian government included ID and mental illness in the disability identification survey. This screening survey was conducted by nonmedical personnel. However, the screening questionnaire was designed with the help of consultants in the field. The questionnaire was designed using International Classification of Diseases-10 based criteria of ID diagnosis, in which it is referred as a significantly subaverage intellectual functioning, slow development, during the developmental period and deficit in adaptive behavior. The consultants were medical doctors and experienced in disability survey. The questionnaire was field tested and validated before use. ${ }^{[21]}$ Consultants also assisted with sample size calculation. Multi-stage sampling with randomization was applied in selecting villages at the district level, and for districts at the state level, in order to minimize selection bias. Geographically, the entire country was covered except those living in the interior villages of Nagaland, Andaman and Nicobar, Leh and Kargil Districts of Jammu Kashmir due to political circumstances $(<1 \%$ of the Indian population also lives in these locations). Data were collected from 45,571 households in 4637 rural villages, and 24,731 households in 3354 urban blocks. Completed in 6 months, the survey began in July and ended in December of 2002. Data are presented on several continuous and categorical variables in tables and the appendix while variables and key terms were explained in the text. ${ }^{[21]}$ For this research, data were taken from the text of the report on age, gender, and residential settings and tables developed for statistical analysis. Data were also broken in two major categories children (below 18 years) and adults (18 years and above) for testing the hypothesis.

\section{Statistical analysis}

Statistical Package for Social Science (SPSS) - 21, (IBM) was used for analysis. Spearman correlation (@) was computed for the prevalence of ID and age among children and adults in rural and urban settings to determine associations. Z-test was used to determine differences between ID prevalence in rural and urban settings at specific age groups to determine any significant differences. Analysis of variance (ANOVA) was used to determine associations between the mean ages and prevalence rates stratifying for age groups. Association of children and adult age groups with the prevalence of ID in rural and urban populations was examined with simple linear regression analyses. ${ }^{[12]}$

\section{Results}

Distribution of prevalence across age groups indicated that the age range with the highest levels of ID was 5 through 35 years in rural areas and between 5 and 39 years in the urban setting. The peak rates for the rural setting were in the 15-19 year age group $(172 / 100,000)$ higher than the peak for the urban setting $(165 / 100,000)$, which was in the 10-14 years age group. The urban peak was, however, more diffuse (10-19) as the prevalence for the 15-19 years group was 164 [Table 1]. ID prevalence differs significantly for three age groups between rural and urban population: Age group 5-9 $(z=-2.322, P=0.020), 35-39(z=-2.315, P=0.020)$, and $45-49(z=-3.160, P=0.001)$ [Table 1].

The analysis, using spearman rho, indicated that the prevalence of ID in children was significantly positively associated with age in the rural $(\varrho=0.981, P=0.019)$ but not significantly so $(\varrho=0.834, P=0.166)$ in the urban population. Whereas, prevalence of ID in adults is significantly inversely associated with age in both rural $(\varrho=-0.954, P=0.001)$ and urban $(\varrho=-0.957, P=0.001)$ areas [Figures 1 and 2, Table 2]. 


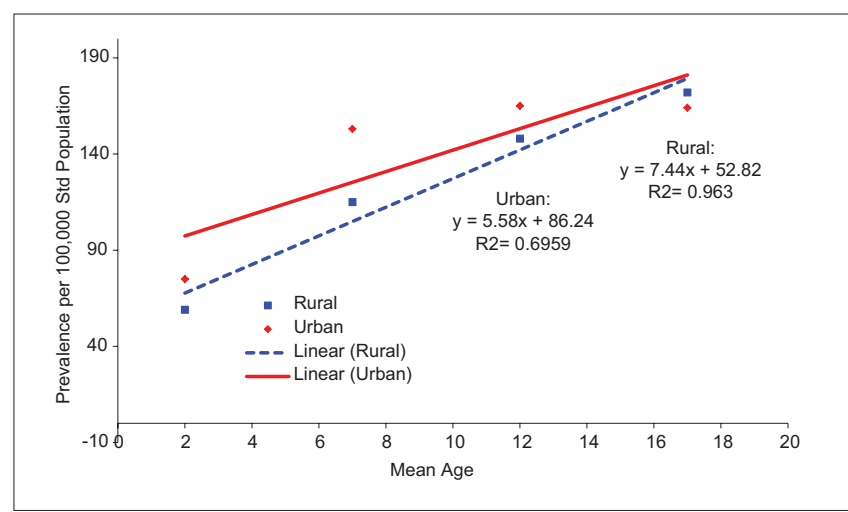

Figure 1: Prevalence of intellectual disabilities among rural and urban children in India (constructed from Table 1)

In children, ANOVA $(F=52.063, P=0.019)$ indicated strong association between age and prevalence of ID in the rural population, where adjusted $R^{2}=0.945$, demonstrates that $94.5 \%$ of the variance in ID prevalence in children is explained by age [Table 3]. In adults, ANOVA $(F=70.658$, $P=0.000$ ) indicated strong association between age and prevalence in the rural population where adjusted $R^{2}=0.897$, demonstrating that $89.7 \%$ of the variance in prevalence is explained by age in rural settings. Similarly, ANOVA $(F=77.022, P=0.000)$ indicated strong association between age and ID prevalence in the urban population among adults, where adjusted $R^{2}=0.905$ demonstrates that $90.5 \%$ of the variance in ID prevalence is explained by age in the urban population. There was no significant association $(P=0.166)$ between age and ID prevalence among children in the urban setting [Table 3]. When analyzed for the total in the two environments, there were significant associations in both the rural ( $F$ $\left.=15.657, R^{2}=0.550, P=0.002\right)$, and urban $\left(F=25.188, R^{2}\right.$ $=0.668, P=0.000)$ settings. However, the model fit was less, indicating that the covariates may be more mutually diverse and independent of one another.

The linear regression equation was obtained for predicting the prevalence of ID in rural and urban population on the basis of the age. According to this predictive model, age increases of 1 year significantly predicted an increase in prevalence of 7.440 children/100,000 $(\mathrm{CI}=3.003$ through 11.877), and prevalence decrease of 3.203 adults $(\mathrm{CI}=-4.104$ through -2.302$) / 100,000$ in rural population. In the urban setting, the model significantly predicted an ID prevalence decrease of 3.033/100,000 $(\mathrm{CI}=-3.851$ through -2.216$)$ per mean year increase in age among adults. In urban children, there was no significant prediction $(\mathrm{CI}=-5.642$ through 16.802$)$ with the wide confidence limits also indicating that there may be confounders or multiple covariates, of age for predicting ID in that setting. Overall, age significantly inversely predicted ID prevalence in both rural (adjusted $B=-2.165$,

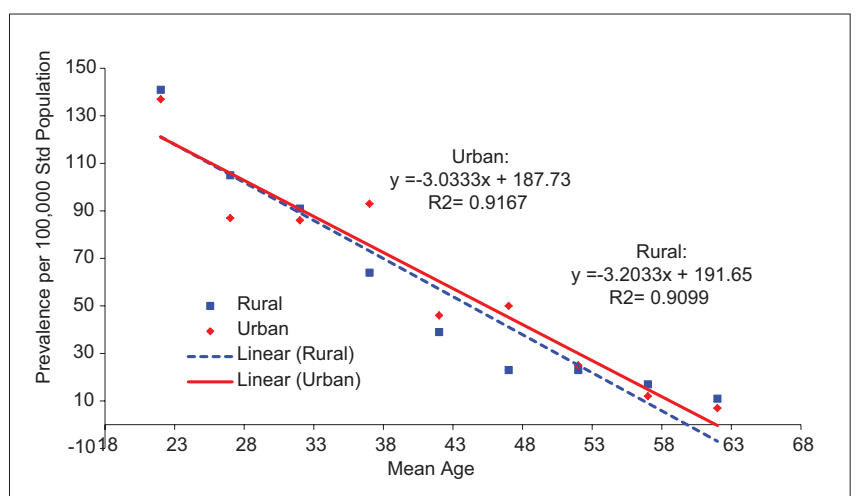

Figure 2: Prevalence of adult intellectual disabilities in rural and urban adults in India (constructed from Table 1)

Table 1: Prevalence of ID in different age groups in India data from NSSO report: Cases per 100,000

\begin{tabular}{lccccccc}
\hline $\begin{array}{l}\text { Age } \\
\text { groups }\end{array}$ & $\begin{array}{c}\text { Mean } \\
\text { age }\end{array}$ & Rural & Urban & Total & Mean & $\boldsymbol{Z}$ & $\boldsymbol{P}$ \\
\hline $0-4$ & 2 & 59 & 75 & 134 & 67 & -1.382 & 0.167 \\
$5-9$ & 7 & 115 & 153 & 268 & 134 & -2.322 & 0.020 \\
$10-14$ & 12 & 148 & 165 & 313 & 156.5 & -0.961 & 0.337 \\
$15-19$ & 17 & 172 & 164 & 336 & 168 & 0.4368 & 0.659 \\
$20-24$ & 22 & 141 & 137 & 278 & 139 & 0.240 & 0.810 \\
$25-29$ & 27 & 105 & 87 & 192 & 96 & 1.299 & 0.193 \\
$30-34$ & 32 & 91 & 86 & 177 & 88.5 & 0.376 & 0.703 \\
$35-39$ & 37 & 64 & 93 & 157 & 78.5 & -2.315 & 0.020 \\
$40-44$ & 42 & 39 & 46 & 85 & 42.5 & -0.759 & 0.447 \\
$45-49$ & 47 & 23 & 50 & 73 & 36.5 & -3.160 & 0.001 \\
$50-54$ & 52 & 23 & 25 & 48 & 24 & -0.288 & 0.771 \\
$55-59$ & 57 & 17 & 12 & 29 & 14.5 & 0.928 & 0.3523 \\
60 above & 62 & 11 & 7 & 18 & 9 & 0.942 & 0.347 \\
Total & Overall & 1008 & 1100 & 2108 & 1054 & -2.0144 & 0.044 \\
\hline NSSO: National Sample Survey Organization, ID: Intellectual disabilities
\end{tabular}

Table 2: Correlation of ID prevalence with age in children, adult population in rural and urban India

\begin{tabular}{|c|c|c|c|c|c|}
\hline \multirow[t]{2}{*}{ Categories } & \multirow{2}{*}{$\begin{array}{c}\text { Age } \\
\text { Mean } \pm \text { SD }\end{array}$} & \multicolumn{4}{|c|}{ Prevalence } \\
\hline & & Settings & Mean \pm SD & Rho (@) & $P$ \\
\hline \multirow{2}{*}{$\begin{array}{l}\text { Children } \\
\text { (below } \\
18 \text { years) }\end{array}$} & $9.50 \pm 6.45$ & Rural & $123.5 \pm 48.93$ & 0.981 & 0.019 \\
\hline & & Urban & $139.25 \pm 43.17$ & 0.834 & 0.166 \\
\hline \multirow{2}{*}{$\begin{array}{l}\text { Adults } \\
\text { (18 years } \\
\text { and above) }\end{array}$} & $42.00 \pm 13.69$ & Rural & $57.11 \pm 45.98$ & -0.954 & 0.001 \\
\hline & & Urban & $60.33 \pm 43.38$ & -0.957 & 0.001 \\
\hline
\end{tabular}

$C I=-3.369$ through -0.961$)$ and urban $(B=-2.408$, $\mathrm{CI}=-3.464$ through -1.352 ) environments.

\section{Discussion}

This study finds that age is an important factor for ID in rural children, and among adults in both rural and urban populations in India. ID is linearly positively associated with age in rural children. However, it is inversely 
Table 3: Regression analysis showing association of age with prevalence of ID in rural and urban settings in India

\begin{tabular}{|c|c|c|c|c|c|c|c|}
\hline \multirow{3}{*}{$\begin{array}{l}\text { Age } \\
\text { groups }\end{array}$} & \multirow[t]{3}{*}{ Setting $^{b}$} & \multicolumn{3}{|c|}{ Model (ANOVA) } & \multicolumn{3}{|c|}{ Regression } \\
\hline & & \multirow[t]{2}{*}{$F$} & \multirow[t]{2}{*}{$P$} & \multirow[t]{2}{*}{$R^{2 c}$} & \multirow[t]{2}{*}{$B_{1}$} & \multicolumn{2}{|c|}{$95 \% \mathrm{Cl}$} \\
\hline & & & & & & Lower & Upper \\
\hline \multirow{2}{*}{$\begin{array}{l}\text { Under } \\
18 \text { years }\end{array}$} & Rural & 52.063 & 0.019 & 0.945 & 7.440 & 3.003 & 11.877 \\
\hline & Urban & 4.577 & 0.166 & 0.544 & 5.580 & -5.642 & 16.802 \\
\hline \multirow{2}{*}{$\begin{array}{l}19 \text { years } \\
\text { and more }\end{array}$} & Rural & 70.658 & 0.000 & 0.897 & -3.203 & -4.104 & -2.302 \\
\hline & Urban & 77.022 & 0.000 & 0.905 & -3.033 & -3.851 & -2.216 \\
\hline \multirow[t]{2}{*}{ Total (all) } & Rural & 15.654 & 0.002 & 0.550 & -2.165 & -3.369 & -0.961 \\
\hline & Urban & 25.188 & 0.000 & 0.668 & -2.408 & -3.464 & -1.352 \\
\hline
\end{tabular}

aPredictor variable: mean age for group, ${ }^{\mathrm{b}}$ Dependent variable: ID prevalence, 'Adjusted values are used. Cl: Confidence interval, ANOVA: Analysis of variance, ID: Intellectual disabilities

associated with age in rural and urban adult populations. The cumulative prevalence of ID in the overall population was found to be 10.5 cases/1000, with $10.08 / 1000$ in rural, and 11/1000 in the urban population. These findings are consistent with several epidemiological studies. ${ }^{[3-10,14,22,23]}$ However, ID is not significantly associated with, nor predicted by age for children in urban areas. The reasons for these differences are unknown, with our models indicating possible confounders or covariates (factors) may be involved.

The prevalence rate of ID was higher among urban children until the age of 14 years after which it peaked higher in rural children than urban in the 15-19 years age group. However, the adult population between age 20 and 34 in rural setting showed slightly higher prevalence than urban. From 35 years of age, adults in rural population had a lower rate of ID than the urban. Despite that the urban population has better health facilities and awareness of disabilities while rural population suffers with poor facilities, lack of identification, referral, health, and low level of awareness, the reasons for observed differences in prevalence rates are unclear. ${ }^{[3,15,16,24-27]}$ Prevalence of ID gradually drops in adults from the age of 20 years in both rural and urban population. However, the literature indicates some studies of covariates of ID ${ }^{[28-32]}$ These studies have been mostly based on clinical and not necessarily covariates from a population perspective.

There are significantly higher prevalence rates of ID in children compared to adults. The correlates of these discrepancies are unknown ${ }^{[12]}$ and call for empirical investigations to determine the risk factors. This survey may have identified people with more severe ID, which may be related to issues with sensitivity of the survey instruments used, case identification, access to data sources, and/or measurement of health indicators. People with severe ID have shorter life expectancy than those with less severe (IQ above 50) or no ID despite developments in medical care, health facilities, rehabilitation, and public health services that focus on ID. ${ }^{[33-46]}$ In addition, people with ID tend to have higher risks for other social, behavioral, and health issues than those who are healthy. ${ }^{[77-53]}$

\section{Limitations and confounding factors}

Other developmental disabilities, such as Autism, Attention Deficit Hyperactive Disorder, and Tourette syndrome closely match with ID in characteristics and features and also show high comorbidity. Other neurological, genetic metabolic, and psychiatric disorders such as cerebral policy, Down syndrome, William Syndrome, Prader-Willi syndrome, Fragile- $X$ syndrome, Klinefelter syndrome, mucopolysaccharidosis, and childhood schizophrenia in children, vascular dementia originated from stroke, Alzheimer and Parkinson's disease in adults often show some features of ID. ${ }^{[54]}$ However, the questionnaire, having been designed and validated by experts, had less chance of falsifying non-ID as ID, but it cannot be denied that few cases of similar features might have been mixed up in the data because of survey data collector's possibly limited training on ID, or other errors in data collection.

\section{Conclusion}

Findings in this study are similar to other epidemiological studies. ${ }^{[12,55-57]}$ This study was able to demonstrate relationships between age and prevalence of ID in rural/urban populations. However, this study could not identify prevalence rates with regard to the severity of ID, which is very important for planning purposes. Two-stage epidemiological studies are recommended, to identify specific prevalence rates with each degree of ID, and large epidemiological population studies to identify social, environmental, and biological determinants and correlates. Also, because it is unclear why prevalence among children is significantly higher than among adults, correlates and contexts of ID among children in both rural and urban settings should be studied to identify areas for intervention.

\section{Acknowledgment}

The first author sincerely thanks his coauthors (who are also his professors in public health). They helped him with research design, literature review, data analysis, and preparation of this manuscript. All coauthors have contributed significantly in preparation of this manuscript. The first author also would like to thank his family for continued and unconditional support. 


\section{References}

1. United Nations Children's Fund (UNICEF). The Situation of Children in India. A Profile; 2011. Available from: http://www.unicef.org/india/ The_Situation_of_Children_in_India_-__A_profile_20110630_pdf. [Last cited on 2015 Mar 09].

2. Maulik PK, Harbour CK. Epidemiology of intellectual disability. International Encyclopedia of Rehabilitation. Buffalo, Center for International Rehabilitation Research Information and Exchange; 2010. p. 1-12. Available from: http://www.cirrie.buffalo.edu/encyclopedia/en/ article/144/. [Last cited on 2015 Mar 09].

3. Durkin M. The epidemiology of developmental disabilities in low-income countries. Ment Retard Dev Disabil Res Rev 2002;8:206-11.

4. Kumar SG, Das A, Bhandary PV, Soans SJ, Harsha Kumar HN, Kotian MS. Prevalence and pattern of mental disability using Indian disability evaluation assessment scale in a rural community of Karnataka. Indian J Psychiatry 2008;50:21-3.

5. Srinath S, Girimaji SR. Epidemiology of child and adolescent mental health problems and mental retardation. NIMHANS J 1999;17:355-66.

6. Belmont L. Science and Technology in Mental Retardation. Screening for severely mental retardation in developing countries. The international pilot study on severe childhood disability. London: Metheun; 1986. p. 389-95. [Eric number: ED280234].

7. Mehta P, Joseph A, Verghese A. An epidemiologic study of psychiatric disorders in a rural area in Tamilnadu. Indian J Psychiatry 1985;27:153-8.

8. Narayanan HS. A study of the prevalence of mental retardation in Southern India. Int J Ment Health 1981;10:28-36.

9. Nandi DN, Ajmany S, Ganguli H, Banerjee G, Boral GC, Ghosh A, et al. Psychiatric disorders in a rural community in West Bengal: An epidemiological study. Indian J Psychiatry 1975;17:87-99.

10. Girimaji SC, Srinath S. Perspectives of intellectual disability in India: Epidemiology, policy, services for children and adults. Curr Opin Psychiatry 2010;23:441-6.

11. Lakhan R, Ekúndayò OT. Application of the ecological framework in depression: An approach whose time has come. AP J Psychol Med 2013;14:103-9.

12. Lakhan R, Ekúndayò OT. National Sample Survey Organization survey report: An estimation of prevalence of mental illness and its association with age in India. J Neurosci Rural Pract 2015;6:51-4.

13. Maulik PK, Darmstadt GL. Childhood disability in low-and middle-income countries: Overview of screening, prevention, services, legislation, and epidemiology. Pediatrics 2007;120 Suppl 1:S1-55.

14. Kumar SG, Das A. Are the disability data in India appropriate? Natl Med J India 2009;22:278.

15. Pratap S. Developing Child and Adolescent Psychiatry Workforce for Low- and Middle Income Countries. J Indian Assoc Child Adolesc Ment Health 2008;4:1-4.

16. Edwardraj S, Mumtaj K, Prasad JH, Kuruvilla A, Jacob KS. Perceptions about intellectual disability: A qualitative study from Vellore, South India. J Intellect Disabil Res 2010;54:736-48.

17. Durkin MS, Khan NZ, Davidson LL, Huq S, Munir S, Rasul E, et al. Prenatal and postnatal risk factors for mental retardation among children in Bangladesh. Am J Epidemiol 2000;152:1024-33.

18. Savitz DA, Arbuckle T, Kaczor D, Curtis KM. Male pesticide exposure and pregnancy outcome. Am J Epidemiol 1997;146:1025-36.

19. Emerson E. Poverty and people with intellectual disabilities. Ment Retard Dev Disabil Res Rev 2007;13:107-13.

20. Winkelstein W Jr. Determinants of worldwide health. Am J Public Health 1992;82:931-2.

21. National Sample Survey Organization (NSSO). Ministry of Statistics and Programme Implementation Government of India. Disabled Persons in India, NSS $58^{\text {th }}$ Round (July-December 2002) Report No. 485 (58/26/1). New Delhi; December 2003. Available from: http://www.domain-b. com/economy/general/2005/pdf/Disability_in_India.pdf. [Last cited on 2014 May 03].

22. Kumar SG, Roy G, Kar SS. Disability and rehabilitation services in India: Issues and challenges. J Family Med Prim Care 2012;1:69-73.

23. Chavan BS, Rozatkar AR. Intellectual disability in India: Charity to right based. Indian J Psychiatry 2014;56:113-6.
24. Ali A, Strydom A, Hassiotis A, Williams R, King M. A measure of perceived stigma in people with intellectual disability. Br J Psychiatry 2008;193:410-5.

25. Jain S, Chowdhury V, Juneja M, Kabra M, Pandey S, Singh A, et al. Intellectual disability in Indian children: Experience with a stratified approach for etiological diagnosis. Indian Pediatr 2013;50:1125-30.

26. Srinath S, Girimaji SC, Gururaj G, Seshadri S, Subbakrishna DK, Bhola P, et al. Epidemiological study of child and adolescent psychiatric disorders in urban and rural areas of Bangalore, India. Indian J Med Res 2005;122:67-79.

27. Jauhari P, Boggula R, Bhave A, Bhargava R, Singh C, Kohli N, et al. Aetiology of intellectual disability in paediatric outpatients in Northern India. Dev Med Child Neurol 2011;53:167-72.

28. Persha A, Arya S, Nagar RK, Verma RK. Biological and psychosocial predictors of developmental delay in persons with intellectual disability: Retrospective case-file study. Asia Pac Disabil Rehabil J 2007;18:93-100.

29. Koul R, Al-Yahmedy M, Al-Futaisi A. Evaluation children with global developmental delay: A prospective study at Sultan Qaboos University Hospital, Oman. Oman Med J 2012;27:310-3.

30. O’Dell R, Leafman J, Nehrenz GM Sr, Bustillos D. Health care decision making and adults with intellectual disability: A descriptive survey. AJOB Prim Res 2012;3:8-13.

31. Bertelli M, Scuticchio D, Ferrandi A, Lassi S, Mango F, Ciavatta C, et al. Reliability and validity of the SPAID-G checklist for detecting psychiatric disorders in adults with intellectual disability. Res Dev Disabil 2012;33:382-90.

32. Maw A. Paediatric neurology-history and examination. Adv Clin Neurosci Rehabil 2009;9:34-6. Available from: http://www.acnr.co.uk/ND09/ ACNRND09_Paediatric.pdf. [Last accessed on 2015 Apr 22].

33. Bear MF, Huber KM, Warren ST. The mGluR theory of fragile X mental retardation. Trends Neurosci 2004;27:370-7.

34. Turnock BJ. Public Health What It Is and How It Works. $5^{\text {th }}$ ed. Burlington (MA): Jones and Bartlett Learning; 2012.

35. Cooper SA, Melville C, Morrison J. People with intellectual disabilities: Their health needs differ and need to be recognised and met. Br Med J 2004;329:414-5.

36. Decouflé P, Autry A. Increased mortality in children and adolescents with developmental disabilities. Paediatr Perinat Epidemiol 2002;16:375-82.

37. Kapell D, Nightingale B, Rodriguez A, Lee JH, Zigman WB, Schupf N. Prevalence of chronic medical conditions in adults with mental retardation: Comparison with the general population. Ment Retard 1998;36:269-79.

38. Wilson DN, Haire A. Health care screening for people with mental handicap living in the community. BMJ 1990;301:1379-81.

39. Beange H, McElduff A, Baker W. Medical disorders of adults with mental retardation: A population study. Am J Ment Retard 1995;99:595-604.

40. Katz RT. Are children with cerebral palsy and developmental disability living longer? J Dev Phys Disabil 2009;21:409-24.

41. Patja K, Mölsä P, Iivanainen M. Cause-specific mortality of people with intellectual disability in a population-based, 35-year follow-up study. J Intellect Disabil Res 2001;45 (Pt 1):30-40.

42. Eyman RK, Grossman HJ, Chaney RH, Call TL. The life expectancy of profoundly handicapped people with mental retardation. $\mathrm{N}$ Engl J Med 1990;323:584-9.

43. Patja K, Iivanainen M, Vesala H, Oksanen H, Ruoppila I. Life expectancy of people with intellectual disability: A 35-year follow-up study. J Intellect Disabil Res 2000;44 (Pt 5):591-9.

44. Gustavson KH, Umb-Carlsson O, Sonnander K. A follow-up study of mortality, health conditions and associated disabilities of people with intellectual disabilities in a Swedish county. J Intellect Disabil Res 2005;49:905-14.

45. Patel SK. An empirical study of causes of disability in India. Internet J Epidemiol 2009;6:4-5.

46. Bittles AH, Petterson BA, Sullivan SG, Hussain R, Glasson EJ, Montgomery PD. The influence of intellectual disability on life expectancy. J Gerontol A Biol Sci Med Sci 2002;57:M470-2.

47. Carvill S. Sensory impairments, intellectual disability and psychiatry. J Intellect Disabil Res 2001;45:467-83.

48. Owens PL, Kerker BD, Zigler E, Horwitz SM. Vision and oral health needs of individuals with intellectual disability. Ment Retard Dev Disabil Res Rev 2006;12:28-40. 
49. Emerson E. Commentary: Childhood exposure to environmental adversity and the well-being of people with intellectual disabilities. J Intellect Disabil Res 2013;57:589-600.

50. Emerson E, Brigham P. Exposure of children with developmental delay to social determinants of poor health: Cross-sectional case record review study. Child Care Health Dev 2015;41:249-57.

51. Jansen SL, van der Putten AA, Vlaskamp C. What parents find important in the support of a child with profound intellectual and multiple disabilities. Child Care Health Dev 2013;39:432-41.

52. McCauley D, Gorter JW, Russell DJ, Rosenbaum P, Law M, Kertoy M. Assessment of environmental factors in disabled children 2-12 years: Development and reliability of the Craig Hospital Inventory of Environmental Factors (CHIEF) for Children-Parent Version. Child Care Health Dev 2013;39:337-44.

53. Cooper V, Emerson E, Glover G, Gore N, Hassiotis A, Hastings R, et al. Early intervention for children with learning disabilities whose behaviours challenge. The Challenging Behaviour Foundation, Briefing Paper; November, 2014

54. Katz G, Lazcano-Ponce E. Intellectual disability: Definition, etiological factors, classification, diagnosis, treatment and prognosis. Salud Publica Mex 2008;50 Suppl 2:s132-41.

55. Oeseburg B, Dijkstra GJ, Groothoff JW, Reijneveld SA, Jansen DE. Prevalence of chronic health conditions in children with intellectual disability: A systematic literature review. Intellect Dev Disabil 2011;49:59-85.

56. Maulik PK, Mascarenhas MN, Mathers CD, Dua T, Saxena S. Prevalence of intellectual disability: A meta-analysis of population-based studies. Res Dev Disabil 2011;32:419-36.

57. Lai DC, Tseng YC, Hou YM, Guo HR. Gender and geographic differences in the prevalence of intellectual disability in children: Analysis of data from the national disability registry of Taiwan. Res Dev Disabil 2012;33:2301-7.

How to cite this article: Lakhan $\mathrm{R}$, Ekúndayò OT, Shahbazi M. An estimation of the prevalence of intellectual disabilities and its association with age in rural and urban populations in India. J Neurosci Rural Pract 2015;6:523-8

Source of Support: Nil. Conflict of Interest: None declared. 